\title{
Patient's Transition Experiences from Hospital to Home after an Acute Cardiac Event
}

\author{
Azizah Khoiriyati ${ }^{1,2 *}$, Kusnanto Kusnanto ${ }^{3}$, Ninuk Dian Kurniawati ${ }^{4}$, Al Afik Afik $^{2}$ \\ ${ }^{1}$ Doctoral Student, Faculty of Nursing, Universitas Airlangga, Surabaya, Indonesia; ${ }^{2}$ Department of Emergency Nursing, Faculty \\ of Medicine and Health Sciences, Universitas Muhammadiyah Yogyakarta, Bantul, Indonesia; ${ }^{3}$ Department of Advanced \\ Nursing, Faculty of Nursing, Universitas Airlangga, Universitas Airlangga Hospital, Surabaya, Indonesia; ${ }^{4}$ Department of Basic \\ Nursing, Faculty of Nursing, Universitas Airlangga, Surabaya, Indonesia
}

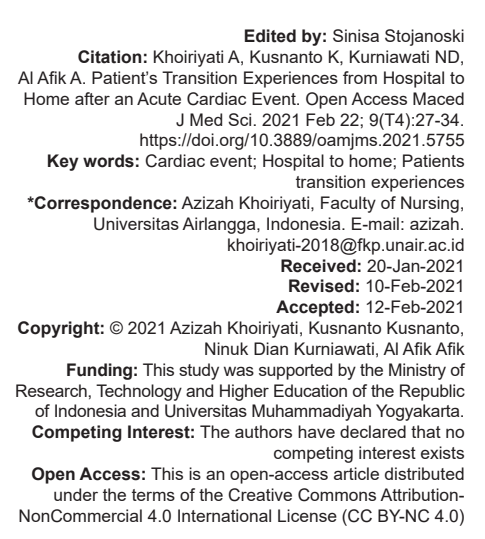

\section{Abstract}

BACKGROUND: Care transition after hospital discharge is challenging for patients and their families. For post an acute cardiac event patients, the $0-14$ days period is a vulnerable period. After hospitalization, patients and their families report having unmet information needs at a time of hospital discharge. It can increase the complication and hospital readmission.

AIM: This study aim to explore the patient's transition experiences from hospital to home after an acute cardiac event.

METHODS: An exploratory qualitative research design with phenomenological approach was used in the study. The data were collected from April to July 2020, using semi-structured interviews with 15 patients diagnosed with acute coronary syndrome (ACS). Transcribed interview data were thematically analyzed.

RESULTS: There are five themes obtained from the study: Positive perception after an acute cardiac event, the changes experienced, the knowledge which was required, the support needs, and expectations and goals.

CONCLUSION: Transition from hospital to home depends on the perceptions of the participants themselves. The experience of transitioning patients from hospital to home was influenced by the existence of support from family, spiritual meaning, and social environment to be able to adapt to health conditions. The finding of this study can assist the nurses in understanding better the needs of patients to prepare the care transition from the hospital to home.

\section{Introduction}

Acute coronary syndrome (ACS) is a disease with high morbidity and mortality [1]. The risk of recurrence is still high, especially in the $1^{\text {st }}$ year [2]. Older age, female gender, and diabetes mellitus are significant predictors of recurrent cardiovascular disease (CVD) events. The incidence of myocardial infarction in the United States in 2018 was 805,000, where 605,000 were new cases and 200.00 (25\%) were recurrent cases [3]. In Indonesia, the highest prevalence for CVD was coronary heart disease, in which the percentage was at $1.5 \%$ [4]. Meanwhile, based on basic health research in 2018, the incidence of heart disease in Indonesia was $2.2 \%$. Yogyakarta is the $3^{\text {rd }}$ largest number in Indonesia for heart disease [5].

The recovery transition period is a complex process for patients. This transition of care is an essential phase, as it can threaten patient safety [6]. The 0-14 days time period is a vulnerable period for post-ACS patients because more than $50 \%$ of hospitalizations are rehospitalized during that time [4]. The transition of care from hospital to home also requires good coordination between various disciplines and coordination with patients and their families [7]. Post-hospitalized heart attack patients often feel inadequately prepared for the hospitalto-home transition [8]. Discharge from the hospital is often accompanied by inadequate information, little instruction, inadequate planning, and lack of coordination among health team members and ineffective communication [9]. It has an impact on the emergence of difficulties in overcoming matters related to the disease and ensures the adaptation process runs well after being discharged from the hospital [10]. If the patient feels a lack of readiness for discharge, it can be a strong predictor of coping difficulties after discharge and readmission to the hospital [11].

The recovery process does not only focus on the disease, but the patients' view of their existence and life transition is much different from before [12]. Psychological problems are also often experienced by post-ACS patients [13]. The recovery process in female participants personally after myocardial infarction is multidirectional. Participants have a desire to develop and take approaches with new perspectives on their life [12]. Moreover, it is crucial to explore the experience of the transition to care felt by patients after a heart attack. The purpose of this study is to explore the experience of transitioning from hospital to home care in participants following ACS. 


\section{Methods}

This study used a qualitative design to explore the experience of transitioning post-ACS patient care from hospital to home. Data were collected at two private hospitals in Yogyakarta, Indonesia. The selection process of participants used a purposive sampling technique. There were 15 participants within 1-2 weeks after ACS treatment at the hospitals who participated in this study. The criteria for participants included were as follows: (1) Patients after treatment for ACS within 1-2 weeks after discharge from hospital, (2) patients who had a previous medical history of heart attack, and (3) the patient's age was more than 40 years old. Participants and researchers had never met before the implementation of this study. The characteristics of the participants are shown in Table 1.

Table 1: Informants' characteristic

\begin{tabular}{llllll}
\hline No. & Age & Gender & Educational background & Marital status & Occupation \\
\hline 1 & 52 & Male & Junior high school & Married & Laborer \\
2 & 56 & Female & Higher education & Married & Housewife \\
3 & 55 & Male & Senior high school & Married & Retired \\
4 & 61 & Male & Vocational high school & Married & Retired \\
5 & 41 & Male & Senior high school & Married & Temporary employer \\
6 & 63 & Male & Senior high school & Married & Retired \\
7 & 65 & Male & Vocational high school & Married & Retired \\
8 & 58 & Male & Senior high school & Married & Part time \\
9 & 62 & Male & Public Islamic high school & Married & Unemployed \\
10 & 47 & Male & Senior high school & Married & Entrepreneur \\
11 & 53 & Male & Junior high school & Married & Unemployed \\
12 & 62 & Male & Senior high school & Married & Retired \\
13 & 56 & Male & Senior high school & Married & Unemployed \\
14 & 55 & Female & Senior high school & Married & Housewife \\
15 & 68 & Female & Higher education & Married & Retired \\
\hline
\end{tabular}

Data collection used semi-structured one-toone interviews through a phone call from April to July 2020. All of the interviews were recorded using audio recording and then were transcribed. By good contact with the researcher, the credibility of the findings is established. The member check is used to compare the suitability of the ideas collected from the data and the participants' opinion. Data analysis used open code software. The data were analyzed using Braun and Clarke's six-step thematic analysis (2006).

This research had been approved by the health research ethics committee team of the Faculty of Nursing, Universitas Airlangga, on letter no. 1915KEPK. All participants had received an explanation and stated that they were willing to participate in the study by signing informed consent. None of the participants refused to participate in this study. All participant identities were removed in this publication for confidentiality.

\section{Results}

The result of qualitative data analysis found that there were five main themes related to the experience of transitioning care from hospital to home in the post-ACS patients: (1) Positive perception after an acute cardiac event, (2) changes experienced, (3) the knowledge which was required, (4) the support needs, and (5) goals and expectations (Table 2).

\section{Theme 1: Positive perception after an} acute cardiac event

This theme illustrates that during the transition from hospital to home care in 1-2 weeks, the perception of the participants really needed to adapt to their new life after a heart attack. This adaptation started when the participants were given the meaning of the transition period, meaning of sick, readiness to return home, and spirituality enhancement.

\section{Subtheme 1.1: Positive perception of the} meaning of the transition period

Participants explained that the transition period from hospital to home was significant as it was a time to adapt to new living conditions after a heart attack. This transition period was a time for recovery so that many habits must be changed or modified to lead to healthier behaviors. The following are quotes from the informant:

"This phase is significant ma'am, the problem is that my so much .... many adaptations of mine... this recovery process is not a direct test..." (Participant 10).

\section{Subtheme 1.2 perception of meaning of sickness}

Participants interpreted their sick condition as a high acceptance and surrender to God. Participants were more grateful for their condition because sickness made them aware, prayed a lot, tried, and got closer to God. The following are excerpts from the participants:

"If I am not in a condition of heart disease may be in the Islamic view, I am looking so arrogant, because I have no fear..." (Participant 4).

\section{Subtheme 1.3 discharge readiness to home}

All participants said that they were ready to go home. However, readiness was more emotional.

Table 2: Overview themes and subthemes

\begin{tabular}{|c|c|}
\hline Themes & Subthemes \\
\hline \multirow[t]{3}{*}{$\begin{array}{l}\text { Positive perception after } \\
\text { an acute cardiac event }\end{array}$} & $\begin{array}{l}\text { 1. Positive perception of the meaning of the transition period } \\
\text { 2. Perception of meaning of sickness }\end{array}$ \\
\hline & 3. Discharge readiness to home \\
\hline & 4. Spirituality enhancement \\
\hline \multirow[t]{4}{*}{ Changes experienced } & 1. Changes in physical activity \\
\hline & 2. Psychological changes \\
\hline & 3. Changes in sleep and rest \\
\hline & 4. Changes in social activities \\
\hline \multirow{3}{*}{$\begin{array}{l}\text { The knowledge which was } \\
\text { required }\end{array}$} & 1. Knowledge of heart disease \\
\hline & 2. Home care methods and strategies \\
\hline & 3. Complementary therapies \\
\hline \multirow[t]{3}{*}{ The support needs } & 1. Family support \\
\hline & 2. Social support from the community \\
\hline & 3. The health insurance existence \\
\hline \multirow[t]{2}{*}{ Goals and expectations } & 1. No recurrence of heart attack \\
\hline & 2. Being able to lifestyle modification \\
\hline
\end{tabular}


Several participants said that the readiness from the aspect of knowledge was still lacking and that the physical readiness felt by the participants was not fully ready. Here is an example of an expression of one of the participants:

“... It has not been yet ma'am ... but I'm ready to go home ... I'm not at home in the hospital ... just aren't coming home ..." (Participant 10).

\section{Subtheme 1.4 spirituality enhancement}

Most of the participants stated that after experiencing illness, their worship and closeness to god had been increasing compared to before being sick. All participants in this study were Muslim. Religious activities increase in intensity and frequency compared to before being sick from starting dhikr and praying to God a lot and praying at night. In addition, two out of 15 participants said that many participants participated in religious activities. The following are quotes from participants:

"Alhamdulillah, since after I got sick, my closeness to my religion was closer rather than before my illness period" (Participant 4).

\section{Theme 2: The changes experienced}

This theme illustrates that all participants experienced changes after a heart attack. These changes include (1) changes in physical activity, (2) psychological changes, (3) changes in sleep and rest, and (4) changes in social activities.

\section{Subtheme 2.1 changes in physical activity}

All participants stated, after experiencing a heart attack at post-hospitalization, there was a different change in physical activity compared to before being sick. Here is an example of a quote from the participants:

"Since this illness ... my breath is, for example, when I took a shower using a dipper ... on the fifth dippers I had to be puffed" (Participant 10).

\section{Subtheme 2.2 psychological changes}

Participants who had a heart attack for the $1^{\text {st }}$ time had a different psychological response compare to participants who had had more than 1 heart attack. Psychological responses such as anxiety, fear, and emotion were felt by some participants. Here is an example of a quote from a participant:

“... every day that I think ... I live the day full of fear because of something uncertain while waiting for the worst to happen..... It's stressful... from the early heart attack until now that's my psychological condition..." (Participant 4).

\section{Subtheme 2.3 change in sleep and rest} pattern

Four participants mentioned that they had trouble in sleeping because they experienced shortness of breath when they were supine and tilted to the left. Sleep comfort was obtained when the sleeping position lied to the right. Participants' strategies for getting enough sleep time by went to bed earlier.

The following excerpts from the participants:

"Sometimes it hurts at night, then if it's tilted to the left it's a bit painful ... but if it's tilted to the right it doesn't..." (Participant 10).

"This week what I have complained about is being puffed .... that breath pattern happened when I lied flat" (Participant 4).

\section{Subtheme 2.4 change in social activities}

Most of the participants' activities after a heart attack were carried out at home. Most of the participants said that social activity had decreased a lot because of the participants' physical condition. There were only two participants who were still active in community social activities.

The following excerpts from the participants:

"Here, there are rules for social activities, if you are 60 years old, your physical condition is not healthy, you are exempted from activities" (Participant 7).

\section{Theme 3: The knowledge which is required}

This theme explains that the knowledge needed by post-treatment participants from the hospital includes (1) knowledge of heart disease (2) home care methods and strategies, and (3) complementary therapies.

\section{Subtheme 3.1 knowledge of heart disease}

Knowledge about the triggers of a heart attack, the symptoms that appear during a heart attack, and the initial action during a heart attack was a material needed by the participants. A heart attack triggers felt by the participants included activities that made them tired, such as continuous activity and activities of looking down and upright while lifting weights, stopping or forgetting to take medication, taking cold showers, and smoking habits. Symptoms of a heart attack that was felt by the participants included a sudden chest pain that was felt like burning or heat that penetrated the back and spread to the left arm accompanied by heavy cold sweat. Initial actions undertaken by participants during a heart attack started to be smeared with wind oil on the chest and back, massage, warm water, set the sitting position, moved the arms upward, by pulling breath and some participants are soon asked for help 
and were taken to the hospital. These following quotes are from a participant:

"... when at heart attack, for example, the skin is not active when you are adamant, kneeling while taking weights, when I stand upright, I started getting dizzy, puffed, hard to take a breath, and got cold sweat ..." (Participant 7).

\section{Subtheme 3.2 home care methods and strategies}

Participants needed knowledge about home care practices for the recovery process and preventing recurrent attacks. Home care included activity, taking medication and drug side effects, stress management, smoking cessation, diet, and control time. Apart from knowledge, strategies that were easy and could be applied at home by patients and their families were also indispensable.

These following quotes are from the participants about how to care at home:

"Yesterday I avoided cigarettes first, but I was legitimate, so I ended up smoking at the very least then I smoked ..." (Participant 10).

The following is a quote from participants about the strategies he had taken so he did not forget to take medicine at home:

"I often set alarms, and i make a patch ... I print it like that so it won't be forgotten ... so every time I take medicine I tick it ..." (Participant 12).

\section{Subtheme 3.3 complementary therapy}

Some participants were asked about the possibility of treatment with a combination of drugs from the hospital and complementary therapies such as herbs. This is the following excerpts from the participants:

"Sorry, for example, I stopped, how do I change the herbs ..." (Participant 10).

\section{Theme 4: The support needs}

This theme illustrates the support obtained from the participants. This support is very helpful in the healing process and recovery process in the participants. This theme consists of three subthemes, including (1) family support, (2) social support from the community, and (3) health insurance.

\section{Subtheme 4.1 family support}

The family support obtained by the participants was enormous, especially participants who lived in the same house with their families. There were those who live in the same house with their spouse (husband/wife) and some who live with their children after their illness.
Such support included the conduct of care at home, mentoring, monitoring, and psychological support (encouragement, motivation, attention, and calming). The following are quotes from the participants:

"My wife and children always control my food, which is appropriate forme... they also prepares a menu that doesn't contain oil" (Participant 3).

\section{Subtheme 4.2 social community support}

Participants received a lot of support and attention from the community. The support was in the form of being released from night patrol activities, and giving attention and wanting participants to take a lot of rest at home. This is the following excerpt from one of the participants:

\begin{abstract}
"My social activities have already been released, because my neighbor also felt a sense of anxiety, so my patrol duty was released" (Participant 4).
\end{abstract}

\section{Subtheme 4.3 the health insurance existence}

All participants received health insurance through BPJS. The existence of the BPJS health facility was beneficial for the participants in the financing process while in the hospital and financing routine controls. This is the following excerpts from the participants:

“... Before this time, I didn't have a BPJS card, I didn't know how to register it since I have a terrible economy condition.... then when I got the guarantee, I took it to the hospital" (Participant 9).

\section{Theme 5: Goals and expectations}

This theme describes the goals and expectations of participants with their disease conditions. There are two subthemes that include (1) no recurrence of heart attack and (2) being able to lifestyle modification.

\section{Subtheme 5.1 no recurrence of heart attack}

All participants had goals in the transition to treatment which included no recurrence/no recurring attacks.

The following excerpts are from the participants:

“... hopefully it won't come back again ..." (Participant 7). modification

Subtheme 5.2 being able to life style

The subtheme of hope for healing from the participants included being able to maintain activities 
at home, exercise regularly, and adhere to a diet, stop smoking, and take regular medication. The following are quotes from the participants:

“... hopefully I can maintain my activities. If I can't do it, I would not force it. When I get exercise, I don't put it off if I can do it routinely. Eating prohibition must be obeyed either..." (Participant 7).

\section{Discussion}

This study illustrates the perception of the transition period after an acute heart attack, called post-STEMI and NSTEMI. Post-ACS adaptation is not an easy thing for the participants. Interpretation of the transition from hospital to home depends on the perceptions of the participants themselves. Most of them believed that going home from the hospital is free of various restrictions. There are those who view the transition period as a time for the recovery process and require a lot of time to rest. The response to the transition process is very individual and dynamic. It is influenced by contextual, situational, and biological factors [14]. In addition, psychosocial factors also influence the transition from hospital to home [15]. Adaptation to the post-ACS transition period can be helped by the cardiac rehabilitation program. Women attendance rates are still suboptimal, although cardiac rehabilitation is beneficial. The cardiac rehabilitation program is considered very helpful in increasing the confidence of female participants and restoring the position of women to their roles and functions in the family and as members of the community [16].

The interpretation of sick conditions will differ from one individual to another. However, most of the participants in this study viewed that with illness, there were many lessons to be learned. After the illness, they increased their worship to increase their self-awareness, spirituality, and closeness to god. It is a positive thing because this awareness makes the participants more accepting their condition. It is in line with a study in Iran which explains that the patient's perspective on themselves can change to the things that are important and valuable in life, due to their unpredictable future [17]. Individuals who have a positive image of cardiac recovery are those who will choose to live, make lifestyle changes, and attend cardiac rehabilitation. Lifestyle changes need a positive attitude, self-commitment, and individual priorities. Another thing that must be encountered by individuals is the existence of significant emotional challenges and challenges in maintaining lifestyle changes [18].

Participants' perceptions of returning home were still limited to an emotional response as indicated by joy and loss of discomfort due to returning home.
Hospital treatment is described as a condition full of discomfort and pain. However, home care tends to make informants feel more comfortable and pleasant. The patients' perceptions of readiness for discharge related to home self-care education and symptom management were closely related to readiness to discharge from the hospital [19]. Perceptions of readiness for discharge correlate with the quality of discharge education. If the education for returning home is good, a more positive perception of readiness for patients will be built [20]. Patients and caregivers must be aware of their health status and treatment to participate in the discharge process [21].

There are a lot of changes experienced by the participants, including physical activity, psychosocial, sleep and rest pattern, and social activities. It was felt in 1-2 weeks after hospitalization. In addition, some participants also experienced discomfort when sleeping on their backs or lying on their left side. The presence of mild pain and intolerance to moderate levels of activity kept the participants at home a lot. Dyspnea in patients with post-myocardial infarction is common and is strongly associated with impaired quality of life, more frequent rehospitalization, and decreased survival [22]. During the transition period, there is usually a loss of network, something meaningful and changes of known objects. The transition phase will experience a period of uncertainty that requires different skills and competencies [14]. Some post-acute care patients who return home may have greater physical and emotional needs [20]. Another study stated that post-percutaneous intervention patients experienced stress, anxiety, and other negative emotions [13].

The need for support is highly expected by patients after a heart attack. This support includes family support, support from the surrounding community and health insurance. Family support includes caring activity during home treatment, monitoring, counseling, and psychological support. This is in line with other study that the family support has a positive impact on the recovery and adaptation after a heart attack [23], encourage participation, and completion of a cardiac rehabilitation program in women [16]. Moreover, attention from the social environment including a sense of empathy and concern as well as given by family makes an endorsement for the participants. This support was felt by all participants in this study. The same study in Indonesia also explained that the collectivist culture in Indonesia provides an advantage for women as they can easily get support from their core family, relatives, or friends [16]. Financial support through health insurance is essential for the sustainability of the health-care process even though low socioeconomic status is not associated with adverse clinical outcomes [24]. In a qualitative study in Denmark, patients in various socioeconomic subgroups felt excluded from cardiac rehabilitation for various reasons [25]. Therefore, there is a need to increase primary prevention in this group [24]. 
Knowledge of heart disease is essential as a basis for participant's knowledge before proceeding to the knowledge of self-care. Posthospitalization patients need information that includes an understanding of the process of their disease, the symptoms associated with the recovery of cardiac events, and the types of physical and emotional adjustments that they would have after being out of the house [8]. One of the factors that influence patient knowledge is their past ACS experience or their coronary heart disease history. In addition, the patients who have a previous history will have the correct interpretation of symptoms [26] by taking a choice to come to the hospital immediately [27]. The gender factor also influences the interpretation of symptoms. Women who have less severe, intermittent, and gradual heart attack symptoms are at increased risk of delayed presentation, diagnosis, and treatment for ACS [28]. The increasing knowledge about the transition phase requires modification of the strategies that have been used to deal with situations and events before the transition that needs to be modified [14]

Home care methods and treatment strategies are essential for patients to be identified and implemented. Home care that participants need to know includes physical activity, taking medication and drug side effects, stress management, smoking cessation, diet, and post-ACS control time. Lifestyle modifications, including a balanced diet, smoking cessation, limited alcohol consumption, and increased physical activity, are recommended for first-line management of coronary artery disease. The American Heart Association/American College of Cardiology recommended the risk of CVD reduction by persuading the patients to follow a healthy diet that emphasize on vegetables, fruits, and whole grains consumption along with $40 \mathrm{~min}$ of moderate to advanced physical activity (3-4 aerobic sessions per week) [29]. Following lifestyle modifications, including quality diet or exercise rehabilitation, have been associated with a lower risk of all factors causing mortality among patients. The studies conducted in Japan suggested that patients have a high level of confidence about smoking cessation, alcohol restriction, and medication adherence. However, they had relatively low levels of confidence regarding the maintenance of blood pressure control, healthy diet, body weight, and regular exercise ( $\geq 3$ times week) [27].

Complementary therapy has been widely used by people since ancient times, especially Indonesians who have many natural ingredients that are frequently used for medicine. There was one informant in this study who used herbs during home care. However, the informants did not discuss that with the doctor while being controlled in the hospital. Most patients did not inform medical practitioners about their use of CAM and up to $90 \%$ of treatment physicians did not discuss CAM use with their patients [30]. The use of CAM (categories of mind body, biological, and manipulative therapies) in acute myocardial infarction was 33\% [31] and in cardiac patients generally ranged from $4 \%$ to $61 \%$ [30]. There is no relationship between the different types and enhancing the use of CAMs health status after AMI [31]. It suggests that there is a need for better education about CAM and communication between patients and doctors or nurses about the benefits and risks of using CAM.

The long-term goal in post-ACS patients is not to have repeated attacks. The readmission rates at 30 days, 60 days, and 90 days were significantly lower in patients who have a control routine compared to those who did not routinely control to the clinic. ACS and heart failure patients who had readmission in 30 days were more than $50 \%$, which they had done at 0-14 days after returning from the hospital [32]. Discharge planning and post-discharge follow-up are examples of transitional care interventions [33]. The existence of a transitional intervention is essential for the adaptation and recovery process in post-ACS patients.

\section{Conclusion}

The transition period is a process of recovery and adaptation that requires correct perceptions, the ability to give meaning to transitions, and understanding of the changes experienced, knowledge and strategies in the treatment process, and requires support. This study also emphasizes the importance of family and community support in the recovery process during the transition from hospital to home care. The post-ACS patient's spirituality, moreover, based on this study, increases after the illness, indicated by the selfawareness and sense of acceptance of the conditions escalation. The results of this study can help healthcare providers to be more understanding of the needs of post-ACS patients, especially in the transition of care from hospital to home. Thus, nurses and other health service providers will be better at preparing for the discharge of post-ACS patients.

\section{Acknowledgments}

The authors acknowledge the help of all participants and the doctoral scholarship (for the first author) from the Ministry of Research, Technology and Higher Education of the Republic of Indonesia and Universitas Muhammadiyah Yogyakarta (for the first author). 


\section{References}

1. Gibler WB, Racadio JM, Hirsch AL, Roat TW. Continuum of care for acute coronary syndrome: Optimizing treatment for ST-elevation myocardial infarction and non-ST elevation acute coronary syndrome. Crit Pathw Cardiol. 2018;17(3):114-38. https://doi.org/10.1097/hpc.0000000000000151 PMid:30044253

2. Abu-Assi E, López-López A, González-Salvado V, RedondoDiéguez A, Peña-Gil C, Bouzas-Cruz N, et al. The risk of cardiovascular events after an acute coronary event remains high, especially during the first year, despite revascularization. Rev Española Cardiol (English Ed). 2016;69(1):11-8. https://doi. org/10.1016/j.rec.2015.06.015

PMid:26342640

3. Benjamin EJ, Virani SS, Callaway CW, Chamberlain AM, Chang AR, Cheng S, et al. Heart disease and stroke statistics 2018 update: A report from the American Heart Association. Circulation. 2018;137(12):e67-492. https://doi.org/10.1161/ cir.0000000000000573

PMid:29386200

4. Riskesdas. Penyajian Pokok-Pokok Hasil Riset Kesehatan Dasar 2013 Depkes RI; 2018.

5. Kemenkes RI. Hasil Utama Riskesdas; 2018.

6. World Health Organization. Transitions of Care. Geneva: World Health Organization; 2016.

7. Weiss ME, Bobay KL, Bahr SJ, Costa L, Hughes RG, Holland DE. A model for hospital discharge preparation: From case management to care transition. J Nurs Adm. 2015;45(12):606-14. https://doi.org/10.1097/nna.0000000000000273

PMid:26502068

8. Barnason S, Zimmerman L, Nieveen J, Schulz P, Young L. Patient recovery and transitions after hospitalization for acute cardiac events: An integrative review. J Cardiovasc Nurs. 2012;27(2):175-91. https://doi.org/10.1097/ jcn.0b013e318239f5f5

PMid:22210146

9. Lin C, Cheng S, Shih S, Chu C, Tjung J. Discharge planning. Int J Gerontol. 2012;6(4):237-40.

10. Demir S, Ozer Z. Evaluation of the quality of life of patients with acute coronary syndrome. J Cardiovasc Nurs. 2019;10(23):138-44.

11. Miller JF, Piacentine LB, Weiss M. Coping difficulties after hospitalization. Clin Nurs Res. 2008;17(4):278-96. https://doi. org/10.1177/1054773808325226 PMid:18927261

12. Wieslander I, Mårtensson J, Fridlund B, Svedberg P. Women's experiences of how their recovery process is promoted after a first myocardial infarction: Implications for cardiac rehabilitation care. Int J Qual Stud Health Well Being. 2016;11:30633. https:// doi.org/10.3402/qhw.v11.30633 PMid:27172514

13. Shen $X$, Zhu X, Wu Y, Zhou Y, Yang L, Wang Y, et al. Effects of a psychological intervention programme on mental stress, coping style and immune function in percutaneous coronary intervention patients. PLoS One. 2018;13(1):e0187745. https:// doi.org/10.1371/journal.pone.0187745

PMid:29357358

14. Meleis Al. Tansitions Theory Midle Range and Situation Specific Theories in Nursing Research and Practice. Berlin, Germany: Springer Publishing Company; 2010.

15. Corona-lobos L, Harduin M, Boivin C. Psychosocial factors associated with hospital-to-home transitions of older people: A review. 2018;7:4. https://doi.org/10.4172/2167-1168.1000466
16. Sutantri S, Cuthill F, Holloway A. A bridge to normal: A qualitative study of Indonesian women's attendance in a phase two cardiac rehabilitation programme. Eur J Cardiovasc Nurs. 2019;18(8):744-52. https://doi.org/10.1177/1474515119864208 PMid:31328533

17. Moshki M, Khajavi A, Minaee S, Vakilian F, Hashemizadeh $H$. Perceived benefits of the disease: A qualitative study of patients' experiences of heart failure. Nurs Health Sci. 2020;22(2):464-71. https://doi.org/10.1111/nhs.12682

18. Nadarajah SR, Buchholz SW, Wiegand DL, Berger A. The lived experience of individuals in cardiac rehabilitation who have a positive outlook on their cardiac recovery: A phenomenological inquiry. Eur J Cardiovasc Nurs. 2017;16(3):230-9. https://doi. org/10.1177/1474515116651977

\section{PMid:27231394}

19. Mabire C, Bachnick S, Ausserhofer D, Simon M, Simon M, Ausserhofer D, et al. Patient readiness for hospital discharge and its relationship to discharge preparation and structural factors: A cross-sectional study. Int J Nurs Stud. 2018;90:13-20. https://doi.org/10.1016/j.jinurstu.2018.09.016 PMid:30522054

20. Susan K, Stichler JF, Ferber L, Catterall K. Patients' perceptions of the quality of discharge teaching and readiness for discharge. Rehabil Nurs. 2015;40(1):30-9. https://doi.org/10.1002/rnj.164

21. Hesselink G, Zegers M, Vernooij-Dassen M, Barach P, Kalkman $C$, Flink M, etal. Improving patient discharge and reducing hospital readmissions by using Intervention Mapping. BMC Health Serv Res. 2014;14:389. https://doi.org/10.1186/1472-6963-14-389 PMid:25218406

22. Arnold S V, Spertus JA, Jones PG. The impact of dyspnea on health-related quality of life in patients with coronary artery disease: Results from the PREMIER registry. Am Heart J. 157(6):1042-9. https://doi.org/10.1016/j.ahj.2009.03.021 PMid: 19464415

23. Gullick J, Krivograd M, Taggart S, Brazete S, Panaretto L, Wu J. A phenomenological construct of caring among spouses following acute coronary syndrome. Med Health Care Philos. 2017;20(3):393-404. https://doi.org/10.1007/ s11019-017-9759-0 PMid:28251445

24. Biswas S, Andrianopoulos N, Duffy SJ, Lefkovits J, Brennan A Walton $A$, et al. Impact of socioeconomic status on clinical outcomes in patients with ST-segment-elevation myocardial infarction. Circ Cardiovasc Qual Outcomes. 2019;2(1):e004979. https://doi.org/10.1161/circoutcomes.118.004979

PMid:30606051

25. Pedersen M, Overgaard D, Andersen I, Baastrup M, Egerod I. Experience of exclusion: A framework analysis of socioeconomic factors affecting cardiac rehabilitation participation among patients with acute coronary syndrome. Eur J Cardiovasc Nurs. 2017;16(8):715-23. https://doi.org/10.1177/1474515117711590 PMid:28513199

26. Ribeiro V, Melão F, Rodrigues JD, Leite SM, Garcia RM, Dias $\mathrm{P}$, et al. Perception of illness symptoms in patients with acute coronary syndrome: A need to improve. Rev Port Cardiol. 2014;33(9):519-23. https://doi.org/10.1016/j.repce.2013.09.020 PMid:25242678

27. Kitakata H, Kohno T, Kohsaka S, Fujino J, Nakano N, Fukuoka, et al. Patient confidence regarding secondary lifestyle modification and knowledge of heart attack' symptoms following percutaneous revascularisation in Japan: A cross-sectional study. BMJ Open. 2018;8(3):e019119. https://doi.org/10.1136/ bmjopen-2017-019119

PMid:29549203

28. Davis LL. A qualitative study of symptom experiences 
of women with acute coronary syndrome. J Cardiovasc Nurs. 2017;32(5):488-95 https://doi.org/10.1097/ jcn.0000000000000381

PMid:27870722

29. Van Horn L, Carson JA, Appel LJ, Burke LE, Economos C Karmally $\mathrm{W}$, et al. Recommended dietary pattern to achieve adherence to the American heart association/American college of cardiology (AHA/ACC) guidelines: A scientific statement from the American Heart Association. Circulation. 2016;134(22):e50529. https://doi.org/10.1161/cir.0000000000000469 PMid:27789558

30. Grant SJ, Bin YS, Kiat H, Chang DH. The use of complementary and alternative medicine by people with cardiovascular disease: A systematic review. BMC Public Health. 2012;12(1):299. https://doi.org/10.1186/1471-2458-12-299

PMid:22536991
31. Shafiq A, Jayaram N, Gosch KL, Spertus JA, Buchanan DM, Decker $\mathrm{C}$, et al. The association between complementary and alternative medicine and health status following acute myocardial infarction. Clin Cardiol. 2016;39(8):440-5. https:// doi.org/10.1002/clc.22559

PMid:27244586

32. Bumpus SM. Transitional care to reduce cardiac readmissions: 5 -year results from the BRIDGE clinic. J Fam Med Dis Prev. 2017;3(3):3-9. https://doi.org/10.23937/2469-5793/1510062

33. Kamermayer AK, Leasure AR, Anderson L. The effectiveness of transitions-of-care interventions in reducing hospital readmissions and mortality: A systematic review. Dimens Crit Care Nurs. 2017;36(6):311-6. https://doi.org/10.1097/ dcc. 0000000000000266

PMid:28976480 